\title{
Boezem, Pompa, dan Pintu Air sebagai Pengendali Banjir di Kali Balong Kecamatan Tandes Kota Surabaya
}

\author{
Dwi Indriyani ${ }^{1 *}$, S. Kamilia Aziz ${ }^{1}$, Putra Mu'min Mubarok ${ }^{1}$ \\ Departemen Teknik Infrastruktur Sipil, Institut Teknologi Sepuluh Nopember, Surabaya ${ }^{1}$ \\ Koresponden*, Email: d.indriyani@.ce.its.ac.id
}

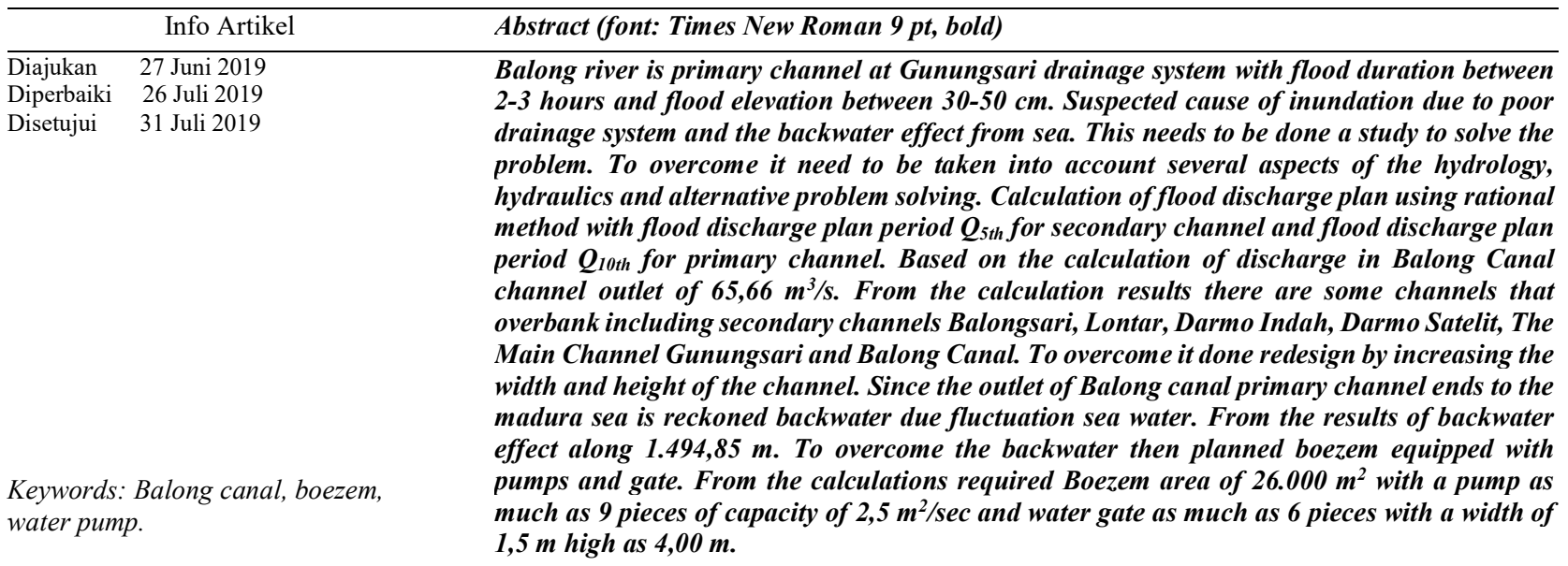

Abstrak

Saluran Primer Kali Balong merupakan sistem Gunungsari yang banjirnya cukup tinggi dengan lama genangan antara 2-3 jam dan tinggi genangan antara 30-50 cm. Diduga penyebab genangan akibat buruknya sistem drainase yang ada ditambah dengan adanya pengaruh backwater. Hal ini perlu dilakukan kajian untuk menanggulangi permasalahan tersebut. Untuk menanggulanginya perlu diperhitungkan beberapa aspek yaitu aspek hidrologi, hidrolika dan alternatif pemecahan masalah. Perhitungan debit rencana menggunakan metode rasional dengan debit $Q_{5}$ untuk saluran sekunder dan $Q_{10}$ untuk saluran primer. Berdasarkan hasil perhitungan debit di outlet saluran Kali Balong sebesar $65,66 \mathrm{~m}^{3} /$ det. Dari hasil perhitungan terdapat beberapa saluran yang meluber diantaranya saluran sekunder Balongsari, Lontar, Darmo Indah, Darmo Satelit, saluran primer Gunungsari dan Kali Balong. Untuk menanggulanginya dilakukan redesign dengan menambah lebar dan tinggi saluran. Outlet saluran primer Kali Balong bemuara ke Selat Madura maka diperhitungkan backwater akibat pasang surut air laut. Hasil perhitungan panjang pengaruh sepanjang $1.494,85 \mathrm{~m}$ dan untuk mengatasi backwater maka direncanakan boezem yang dilengkapi pompa dan pintu. Dari hasil perhitungan dibutuhkan Boezem seluas $26.000 \mathrm{~m}^{2}$ dengan pompa sebanyak 9 buah kapasitas 2,50

Kata kunci: Kali Balong, boezem, $\mathrm{m}^{2} /$ detik dan pintu air sebanyak 6 buah dengan lebar 1,50 setinggi $4,00 \mathrm{~m}$ untuk mengatasi pompa air banjir.

\section{Pendahuluan}

Saluran primer Kali Balong merupakan sistem Gunungsari yang berada di wilayah Surabaya Barat. Catchment area saluran primer Kali Balong meliputi Kecamatan Tandes, dan Benowo. Debit air yang mengalir di saluran Kali Balong berasal dari Saluran Primer Gunungsari dan Saluran Sekunder Balongsari. Berdasarkan info dari media elektronik harian Surabaya, apabila terjadi hujan dengan intensitas yang tinggi seringkali menimbulkan banjir di catchment area saluran sekunder Balongsari dan Saluran Primer Kali Balong.
Ketinggian air mulai 30 - $50 \mathrm{~cm}$. Penyebabnya diduga akibat buruknya sistem drainase dikawasan tersebut. Saluran Primer Gunungsari yang relatif datar ditambah dengan pengaruh backwater mengakibatkan permasalahan banjir dan perlu dikaji dengan mencari solusi terbaik. Perencanaan Boezem dilengkapi pompa dan pintu air di wilayah Kali Balong memungkinkan untuk dikaji di kawasan tersebut. Oleh karena itu, Studi ini membahas tentang Perencanaan pintu air dilengkapi pompa dan boezem di wilayah Kali Balong. 


\section{Metode}

Metodologi yang digunakan dalam studi ini adalah sebagai berikut:

A. Survei Lapangan

Survei lapangan dilakukan bertujuan untuk mengetahui kondisi di lapangan dengan meninjau saluran tersier, sekunder, letak boezem, pompa dan pintu air. dari hasil survei ini dipergunakan sebagai pertimbangan analisis perencanaan boezem, pompa dan pintu air di Kali Balong Kecamatan Tandes kota Surabaya.

B. Analisis Hidrologi

Kajian hidrologi berkaitan dengan data hidrologi yang telah didapat sebelumnya. Data-data hidologi tersebut digunakan untuk merencanakan debit banjir rencana dengan periode ulang tertentu.

C. Analisis Hidrolika

Kajian hidrolika perencanaan dimensi saluran meliputi:

1. Perhitungan kapasitas saluran.

2. Perbandingan kapasitas saluran dengan debit rencana.

3. Perhitungan pengaruh backwater.

D. Pemecahan Masalah

Setelah membandingkan debit banjir dengan kapasitas saluran, kita dapat memperkirakan solusi apa yang dapat digunakan untuk menanggulangi banjir. Beberapa solusi yang dapat digunakan adalah sebagai berikut:

a. Pelebaran kapasitas saluran

Pelebaran kapasitas saluran dilakukan pada saluransaluran yang belum mampu menampung debit rencana, baik itu saluran tersier, sekunder maupun primer.

b. Evaluasi kapasitas pompa

Pada bagian hilir sudah ada 8 pompa dengan kapasitas masing-masing $2 \mathrm{~m}^{3} /$ detik, sehingga total $16 \mathrm{~m}^{3} /$ detik. Kapasitas akan dievaluasi apakah sudah cukup atau perlu ditambah kapasitasnya.

c. Pembangunan boezem

Pada dataran rendah dengan pengaruh backwater pasang surut air laut, air sangat sulit dapat mengalir secara gravitasi ke bagian hilir (laut) pada saat banjir terjadi bersama pasang air laut [1]. Berdasarkan data pasang surut [2] untuk Kali Balong pasang tertinggi berada di atas muka air tertinggi saluran, sehingga tidak mungkin untuk mengalirkan secara gravitasi. Oleh karena itu perlu dibantu dengan keberadaan boezem untuk menampung air sementara, kemudian dipompa ke laut.

\section{d. Evaluasi Pintu}

Bagian hilir sudah ada pintu selebar $1,50 \mathrm{~m}$ berjumlah 6 buah. Keberadaan pintu ini akan dievaluasi apakah masih cukup atau perlu ditambah. Demikian juga dengan lokasinya, apakah tetap di lokasi awal atau perlu dipindah ke lokasi yang lain.

\section{Hasil dan Pembahasan}

A. Analisis Hidrologi

Analisis hidrologi bertujuan untuk mengetahui debit banjir rencana pada saluran yang ditinjau. Pada perencanaan ini debit banjir rencana dihitung menggunakan metode rasional.

1. Analisis Curah Hujan Rata-rata Wilayah

Dalam merencanakan boezem, pompa dan pintu air di Kali Balong, sebagai langkah awal yang dilakukan adalah pengumpulan data curah hujan di stasiun penangkar hujan [3][4]. Pada kawasan ini hanya ada satu alat penangkar hujan yang berpengaruh yaitu Stasiun Kandangan. Sehingga perlu mengambil data hujan yang diperoleh dari Stasiun Kandangan tersebut. Pada Tabel 1 disajikan data curah hujan pada stasiun pengamat sejak tahun 2000 sampai 2014 [5].

Tabel 1. Perhitungan curah hujan maksimum stasiun Kandangan.

\begin{tabular}{|c|c|c|c|c|}
\hline \multicolumn{4}{|c|}{ Stasiun } & \multirow{2}{*}{$\begin{array}{l}\text { Curah Hujan } \\
\text { Wilayah }\end{array}$} \\
\hline Tahun & Bulan & Tanggal & Kandangan & \\
\hline 2000 & Jan & 14 & 110 & 110 \\
\hline 2001 & Jan & 15 & 124 & 124 \\
\hline 2002 & Jan & 30 & 105 & 105 \\
\hline 2003 & Des & 3 & 117 & 117 \\
\hline 2004 & Feb & 10 & 90 & 90 \\
\hline 2005 & Feb & 10 & 90 & 90 \\
\hline 2006 & Jan & 14 & 130 & 130 \\
\hline 2007 & Mar & 8 & 97 & 97 \\
\hline 2008 & Des & 13 & 120 & 120 \\
\hline 2009 & Mar & 6 & 78 & 78 \\
\hline 2010 & Des & 3 & 127 & 127 \\
\hline 2011 & Nop & 9 & 79 & 79 \\
\hline 2012 & Jan & 30 & 82 & 82 \\
\hline 2013 & Jan & 15 & 65 & 65 \\
\hline 2014 & Mar & 5 & 81 & 81 \\
\hline
\end{tabular}

Sumber: Hasil analisis

2. Perhitungan Parameter Statistik

Sebelum dilakukan perhitungan distribusi probabilitas dari data yang tersedia, dilakukan uji parameter statistik terlebih dahulu terhadap data yang ada, sebab masing-masing distribusi (Distribusi Normal, Gumbel dan Log Person Type III) memiliki sifat-sifat khas, sehingga setiap data hidrologi harus diuji kesesuaiannya dengan sifat statistikanya [6]. 
Pemilihan distribusi yang tidak tepat dapat menyebabkan kesalahan perkiraan yang mungkin cukup besar baik over estimate maupun under estimate yang keduanya tidak diinginkan. Hasil perhitungan awal parameter statistik dapat dilihat pada Tabel 2.

Tabel 2. Perhitungan Parameter Statistik

\begin{tabular}{cclcc}
\hline \multirow{2}{*}{ Distribusi } & $\begin{array}{c}\text { Parameter } \\
\text { Statistik }\end{array}$ & \multicolumn{2}{c}{ Hasil } & Status \\
\hline \multirow{2}{*}{ Normal } & $\mathrm{Cs}=0$ & $\mathrm{CS}=$ & 0.03 & tidak \\
& $\mathrm{Ck}=3$ & $\mathrm{CK}=$ & 2.26 & memenuhi \\
\multirow{2}{*}{ Gumbel } & $\mathrm{Cs}=1.14$ & $\mathrm{CS}=$ & 0.03 & Tidak \\
& $\mathrm{Ck}=5.4$ & $\mathrm{CK}=$ & 2.26 & memenuhi \\
Log Pearson Type & $\mathrm{Cs}=$ Fleksibel & $\mathrm{CS}=$ & -0.2 & \multirow{2}{*}{ OK } \\
III & $\mathrm{Ck}=$ Fleksibel & $\mathrm{CK}=$ & 2.54 & \\
\hline
\end{tabular}

Sumber: Hasil analisis

\section{Uji Kecocokan Distribusi}

Diperlukan pengujian parameter untuk menguji kecocokan distribusi frekuensi sampel data terhadap fungsi distribusi peluang yang diperkirakan dapat mewakili distribusi frekuensi tersebut. Ada 2 jenis uji kecocokan yaitu uji kecocokan Chi Kuadrat dan Smirnov Kolmogorov [3],[4].

\section{a. Uji Chi Kuadrat}

Parameter yang digunakan dalam pengambilan keputusan Chi-Kuadrat adalah $\chi^{2}$. Perhitungan parameter $\chi^{2}$ disajikan sebagai berikut:

Perhitungan jumlah sub-group

Diketahui:

$$
\begin{aligned}
\mathrm{n} & =15 \\
\mathrm{G} & =1+1,33 \ln \mathrm{n} \\
\mathrm{G} & =1+1,33 \ln 15 \\
& =4.907 \approx 5 \text { group }
\end{aligned}
$$

\begin{tabular}{|c|c|c|c|c|c|c|c|}
\hline $\mathrm{NO}$ & \multicolumn{3}{|c|}{ Nilai Batas } & $\mathrm{Oi}$ & $\mathrm{Ei}$ & $(\mathrm{Oi}-\mathrm{Ei})^{2}$ & $\chi^{2}$ \\
\hline 1 & & $\mathrm{X}$ & $\leq 1,911$ & 4 & 3 & 1,000 & 0,33 \\
\hline 2 & $1,911<$ & X & $\leq 1,965$ & 3 & 3 & 0,000 & 0,00 \\
\hline 3 & $1,965<$ & $\mathrm{X}$ & $\leq 2,013$ & 1 & 3 & 4,000 & 1,33 \\
\hline 4 & $2,013<$ & X & $\leq 2,068$ & 3 & 3 & 0,000 & 0,00 \\
\hline 5 & & $\mathrm{X}$ & $>2,068$ & 4 & 3 & 1,000 & 0,33 \\
\hline & & & Jumlah & 15 & 15 & & 1,67 \\
\hline
\end{tabular}

Hasil uji Chi-Kuadrat pada distribusi Log Pearson Type III dapat dilihat pada Tabel 3.

Tabel 3. Perhitungan Chi-Kuadrat

Sumber: Hasil analisis

Dari hasil perhitungan akan diterima apabila nilai ChiKuadrat teoritis $>$ nilai Chi-Kuadrat hitung. Dari perhitungan di atas diperoleh nilai 5,991 > 1,67, sehingga distribusi teoritis dapat diterima.

\section{b. Uji Smirnov- Kolmogorov}

Uji Smirnov- Kolmogorov dilakukan dengan maksud untuk menyaring metode distribusi yang lolos dari uji kesesuaian distribusi frekuensi dengan metode Chi- Kuadrat. Hasil Uji Smirnov-Kolmogorov dapat dilihat pada Tabel 4.

Tabel 4. Perhitungan Smirnov Kolmogorov

\begin{tabular}{cccccccc}
\hline $\mathrm{m}$ & $\begin{array}{r}\text { Log } \\
\mathrm{Xi}\end{array}$ & $\mathrm{P}(\mathrm{R})$ & $\begin{array}{l}\mathrm{P}(\mathrm{X} \\
<)\end{array}$ & $\mathrm{f}(\mathrm{t})$ & $\mathrm{P}^{\prime}(\mathrm{X})$ & $\mathrm{P}^{\prime}(\mathrm{X}<)$ & $\mathrm{D}$ \\
\hline 1 & 2,11 & 0,06 & 0,94 & 1,34 & 0,090 & 0,910 & $-0,028$ \\
2 & 2,10 & 0,13 & 0,88 & 1,23 & 0,109 & 0,891 & 0,016 \\
3 & 2,09 & 0,19 & 0,81 & 1,12 & 0,131 & 0,869 & 0,056 \\
4 & 2,08 & 0,25 & 0,75 & 0,96 & 0,169 & 0,832 & 0,082 \\
5 & 2,07 & 0,31 & 0,69 & 0,85 & 0,198 & 0,802 & 0,115 \\
6 & 2,04 & 0,38 & 0,63 & 0,56 & 0,288 & 0,712 & 0,087 \\
7 & 2,02 & 0,44 & 0,56 & 0,34 & 0,367 & 0,633 & 0,071 \\
8 & 1,99 & 0,50 & 0,50 & $-0,03$ & 0,512 & 0,488 & $-0,012$ \\
9 & 1,95 & 0,56 & 0,44 & $-0,38$ & 0,648 & 0,352 & $-0,086$ \\
10 & 1.95 & 0,63 & 0,38 & $-0,38$ & 0,648 & 0,352 & $-0,023$ \\
11 & 1,91 & 0,69 & 0,31 & $-0,81$ & 0,791 & 0,209 & $-0,104$ \\
12 & 1,91 & 0,75 & 0,25 & $-0,87$ & 0,808 & 0,192 & $-0,058$ \\
13 & 1,90 & 0,81 & 0,19 & $-0,99$ & 0,839 & 0,161 & $-0,026$ \\
14 & 1,89 & 0,88 & 0,13 & $-1,05$ & 0,854 & 0,146 & 0,0210 \\
15 & 1,81 & 0,94 & 0,06 & $-1,90$ & 0,971 & 0,029 & $-0,034$ \\
\hline Jumlah & 29,84 & & & & & Dmax $=0,115$ \\
\hline
\end{tabular}

Sumber: Hasil analisis

Dari perhitungan di atas didapatkan Dmaksimum $=0,115$, sedangkan harga Do =0,34 didapatkan dari tabel Nilai Kritis. Karena nilai Dmax lebih kecil dari nilai Do $(0,34>0,115)$. Maka persamaan distribusi Log-Person III yang diperoleh dapat diterima.

4. Perhitungan Curah Hujan Rencana

Hujan rencana adalah hujan tahunan terbesar dengan peluang tertentu yang mungkin terjadi di suatu daerah [3],[4]. Dari hasil uji kecocokan distribusi yang digunakan, maka untuk menghitung curah hujan rencana menggunakan Metode Log-Pearson Type III, dapat dilihat pada Tabel 5.

Tabel 5. Perhitungan Curah hujan rencana

\begin{tabular}{cc}
\hline Periode Ulang (Tahun) & $\begin{array}{c}\text { Curah Hujan Maksimum } \\
(\mathrm{mm})\end{array}$ \\
\hline 2 & 98,28 \\
5 & 117,08 \\
10 & 127,78 \\
\hline
\end{tabular}

Sumber: Hasil analisis

5. Perhitungan Debit Rencana 
Perhitungan debit rencana menggunakan metode rasional [7]. Berikut ini adalah contoh perhitungan debit banjir rencana saluran tersier saluran sekunder Manukan Kulon:

$$
\begin{aligned}
& \mathrm{Q}=\frac{1}{3,6} \cdot \mathrm{C} \cdot \mathrm{I} \cdot \mathrm{A} \\
& \mathrm{Q}=\frac{1}{3,6} \cdot 0,400 \cdot 75,47 \cdot 0,47 \\
& \mathrm{Q}=4,07 \mathrm{~m}^{3} / \text { detik }
\end{aligned}
$$

\section{Keterangan:}

$\mathrm{Q}=$ Debit rencana $\left(\mathrm{m}^{3} / \mathrm{s}\right)$

$\mathrm{C}=$ Koefisien Pengaliran

I = Intensitas Hujan Periode $(\mathrm{mm} / \mathrm{jam})$

A $=$ Luas DAS $\left(\mathrm{km}^{2}\right)$

Hasil debit rencana dapat dilihat pada Tabel 6.

Tabel 6. Perhitungan debit rencana

\begin{tabular}{lcccc}
\hline \multicolumn{1}{c}{ Nama Saluran } & $\mathrm{C}$ & $\begin{array}{c}\mathrm{I} \\
(\mathrm{mm} / \mathrm{jam})\end{array}$ & $\begin{array}{c}\mathrm{A} \\
(\mathrm{Km})\end{array}$ & $\begin{array}{c}\mathrm{Qr} \\
\left(\mathrm{m}^{3} / \mathrm{det}\right)\end{array}$ \\
\hline Sal. Manukan & & & & \\
Kulon & 0,400 & 75,47 & 0,50 & 4,21 \\
Sal. Balongsari & 0,400 & 60,47 & 3,92 & 26,37 \\
Sal. Lontar & 0,345 & 120,60 & 1,57 & 18,19 \\
Sal. Gadelsari & 0,415 & 148,58 & 0,57 & 9,69 \\
Sal. Tubanan & 0,400 & 107,71 & 0,74 & 8,84 \\
Sal. Darmo Indah & 0,385 & 86,99 & 1,25 & 11,67 \\
Sal. Darmo Satelit & 0,435 & 88,03 & 0,87 & 9,22 \\
Sal. Primer & & & & \\
Gunungsari A & 0,400 & 68,50 & 1,09 & 8,28 \\
Sal. Primer & & & & \\
Gunungsari B & 0,400 & 65,99 & 6,74 & 49,45 \\
Sal. Margomulyo & 0,465 & 47,98 & 4,60 & 28,55 \\
Sal. Primer Kali & & & & \\
Balong & 0,480 & 37,53 & 13,11 & 65,66 \\
\hline Sumber: Hasil anatisis
\end{tabular}

Sumber: Hasil analisis

\section{B. Analisis Hidrolika}

Analisis Hidrolika dimaksudkan untuk menghitung kapasitas saluran sekunder dan primer dengan tujuan untuk mengetahui kapasitas saluran yang akan menampung debit rencana. Perhitungan kapasitas saluran ini berdasarkan pada kondisi existing saluran yang ada di lokasi studi.

1. Perhitungan debit kapasitas saluran [7]

- Hasil survey Saluran Sekunder Manukan Kulon

Bentuk penampang persegi:

$$
\begin{aligned}
\mathrm{b} & =2,20 \mathrm{~m} \\
\mathrm{n} & =0,021 \\
\mathrm{~h} & =\mathrm{H} \text { existing - tinggi jagaan }(\mathrm{W}) \\
& =2,10 \mathrm{~m}-0,20 \mathrm{~m} \\
& =1,90
\end{aligned}
$$

- Perhitungan luas penampang saluran

$\mathrm{A}=\mathrm{b} \times \mathrm{h}$

$$
\mathrm{A}=2,20 \times 1,90
$$

$$
\mathrm{A}=4,18 \mathrm{~m}^{2}
$$

- Perhitungan keliling penampang saluran

$\mathrm{P}=\mathrm{b}+2 \mathrm{xH}$

$\mathrm{P}=2,20+2 \times 1,90$

$\mathrm{P}=6,00 \mathrm{~m}$

- Perhitungan jari-jari hidrolis

$$
\begin{aligned}
& \mathrm{R}=\frac{\mathrm{A}}{P} \\
& \mathrm{R}=\frac{4,18}{6,00} \\
& \mathrm{R}=0,70 \mathrm{~m}
\end{aligned}
$$

- Perhitungan kecepatan saluran

$$
\begin{aligned}
\mathrm{V} & =\frac{1}{n} \times \mathrm{R}^{2 / 3} \times \mathrm{I}^{1 / 2} \\
\mathrm{~V} & =\frac{1}{0.021} \mathrm{x}\left(0,70^{2 / 3}\right) \times\left(0,0015^{1 / 2}\right) \\
\mathrm{V} & =1,43 \mathrm{~m} / \text { detik }
\end{aligned}
$$

- Perhitungan debit kapasitas saluran

$$
\begin{aligned}
& \mathrm{Q}=\mathrm{A} \times \mathrm{V} \\
& \mathrm{Q}=4,18 \mathrm{~m}^{2} \times 1,43 \mathrm{~m} / \mathrm{det} \\
& \mathrm{Q}=5,99 \mathrm{~m}^{3} / \mathrm{det}
\end{aligned}
$$

\section{Perhitungan Tinggi Muka Air}

Perhitungan tinggi muka air saluran dari debit rencana dengan asumsi bahwa lebar saluran tetap. Perhitungan tinggi muka air ini menggunakan menu goal seek pada Microsoft excel. Jika tinggi muka air dari debit rencana lebih besar dari tinggi saluran (h) existing maka akan terjadi banjir di saluran tersebut, sehingga perlu dilakukan desain ulang saluran [1]. Adapun perhitungan tinggi muka air dapat dilihat pada Tabel 7.

\section{Perhitungan desain ulang saluran}

Untuk menanggulangi saluran yang meluber perlu dilakukan pemecahan masalah agar saluran dapat menerima debit rencana secara aman dan tidak mengakibatkan banjir. Pemecahan masalah yang sesuai dengan kondisi di lapangan adalah dengan mendesain ulang saluran existing yang meluber, sehingga mampu mengalirkan debit banjir. Alternatif ini dipilih karena di lapangan masih ada lahan yang dapat dipakai untuk melebarkan saluran. Adapun perhitungan desain ulang saluran Tabel 8.

4. Perhitungan tinggi muka air setelah desain ulang saluran

Perhitungan tinggi muka air saluran dari debit rencana dengan asumsi bahwa lebar saluran tetap. Perhitungan tinggi muka ar ini menggunakan menu goal seek pada Microsoft excel. Jika tinggi muka air dari debit rencana lebih besar dari tinggi saluran (h) rencana maka akan terjadi banjir di saluran 
tersebut sehingga perlu dilakukan desain ulang saluran. Adapun Perhitungan tinggi muka air setelah desain ulang saluran dapat dilihat pada Tabel 9.

Tabel 7. Perhitungan Tinggi Muka Air

\begin{tabular}{|c|c|c|c|c|}
\hline \multirow[t]{2}{*}{ Nama Saluran } & $\begin{array}{c}\mathrm{h} \\
\text { exs }\end{array}$ & Q renc & $\begin{array}{c}\mathrm{h} \\
\text { banjir }\end{array}$ & $\begin{array}{c}\Delta \mathrm{h}=\mathrm{h} \\
\text { exs }-\mathrm{h} \\
\text { banjir }\end{array}$ \\
\hline & $(\mathrm{m})$ & $\left(\mathrm{m}^{3} / \mathrm{dtk}\right)$ & (m) & (m) \\
\hline Sal. Sekunder Manukan Kulon 1-43 & 1,90 & 4,21 & 1,34 & 0,56 \\
\hline Sal. Sekunder Lontar 6-7 & 1,90 & 18,19 & 1,77 & 0,13 \\
\hline Sal. Sekunder Lontar 7-10 & 1,60 & 18,19 & 1,78 & $-0,18$ \\
\hline Sal. Sekunder Balong Sari 8-9 & 1,70 & 26,37 & 2,37 & $-0,67$ \\
\hline Sal. Sekunder Balong Sari 9-10 & 1,70 & 26,37 & 2,42 & $-0,72$ \\
\hline Sal. Sekunder Balong Sari 10-11 & 1,80 & 26,37 & 2,35 & $-0,55$ \\
\hline Sal. Sekunder Balong Sari 11-12 & 1,90 & 26,37 & 2,17 & $-0,27$ \\
\hline Sal. Sekunder Balong Sari 12-13 & 1,90 & 26,37 & 2,14 & $-0,24$ \\
\hline Sal. Sekunder Balong Sari 13-14 & 1,90 & 26,37 & 2,14 & $-0,24$ \\
\hline Sal. Sekunder Balong Sari 14-18 & 1,90 & 26,37 & 2,17 & $-0,27$ \\
\hline Sal. Sekunder Gadelsari 15-16 & 1,90 & 9,69 & 0,94 & 0,96 \\
\hline Sal. Sekunder Gadelsari 16-17 & 2,00 & 9,69 & 1,32 & 0,68 \\
\hline Sal. Sekunder Gadelsari 17-18 & 2,00 & 9,69 & 1,32 & 0,68 \\
\hline Sal. Sekunder Balong Sari 18-19 & 1,90 & 26,37 & 1,93 & $-0,03$ \\
\hline Sal. Sekunder Balong Sari 19-20 & 2,00 & 26,37 & 1,86 & 0,14 \\
\hline Sal. Sekunder Balong Sari 20-39 & 2,00 & 26,37 & 1,94 & 0,06 \\
\hline Sal. Sekunder Tubanan 21-22 & 1,16 & 8,84 & 0,99 & 0,17 \\
\hline Sal. Sekunder Tubanan 22-23 & 1,20 & 8,84 & 0,93 & 0,27 \\
\hline Sal. Sekunder Tubanan 23-35 & 1,20 & 8,84 & 0,93 & 0,27 \\
\hline Sal. Sekunder Darmo Indah 24-25 & 1,10 & 11,64 & 1,54 & $-0,44$ \\
\hline Sal. Sekunder Darmo Indah 25-26 & 1,10 & 11,64 & 1,53 & $-0,43$ \\
\hline Sal. Sekunder Darmo Indah 26-28 & 1,20 & 11,64 & 1,54 & $-0,34$ \\
\hline Sal. Sekunder Darmo Harapan 27-28 & 1,68 & 2,19 & 0,64 & 1,05 \\
\hline Sal. Sekunder Darmo Indah 28-33 & 1,30 & 11,64 & 1,22 & 0,08 \\
\hline Sal. Darmo Satelit 29-30 & 1,10 & 9,22 & 1,68 & $-0,58$ \\
\hline Sal. Darmo Satelit 30-31 & 1,20 & 9,22 & 1,63 & $-0,43$ \\
\hline Sal. Darmo Satelit 31-32 & 1,25 & 9,22 & 1,23 & 0,02 \\
\hline Sal. Primer Gunungsari 35-36 & 3,60 & 49,45 & 1,49 & 2,11 \\
\hline Sal. Primer Gunungsari 36-37 & 3,60 & 49,45 & 1,49 & 2,11 \\
\hline Sal. Primer Gunungsari 37-38 & 3,60 & 49,45 & 1,49 & 2,11 \\
\hline Sal. Primer Gunungsari 38-39 & 3,60 & 49,45 & 1,49 & 2,11 \\
\hline Sal. Primer Gunungsari 39-40 & 3,60 & 49,45 & 1,49 & 2,11 \\
\hline Sal. Primer Gunungsari 41-40 & 3,10 & 8,28 & 0,67 & 2,43 \\
\hline Sal. Primer Gunungsari 42-41 & 3,10 & 8,28 & 0,67 & 2,43 \\
\hline Sal. Primer Gunungsari 43-42 & 1,50 & 8,28 & 2,22 & $-0,72$ \\
\hline Sal. Primer Kali Balong 40-44 & 2,45 & 65,66 & 3,28 & $-0,83$ \\
\hline Sal. Primer Kali Balong 44-45 & 2,45 & 65,66 & 3,21 & $-0,76$ \\
\hline Sal. Primer Margomulyo 36-46 & 1,60 & 28,55 & 1,59 & 0,01 \\
\hline Sal. Primer Margomulyo 46-47 & 1,60 & 28,55 & 1,58 & 0,02 \\
\hline Sal. Primer Margomulyo 47-48 & 1,60 & 28,55 & 1,60 & 0,00 \\
\hline Sal. Primer Margomulyo 48-49 & 1,60 & 28,55 & 1,60 & 0,00 \\
\hline Sal. Primer Margomulyo 49-50 & 1,70 & 28,55 & 1,54 & 0,16 \\
\hline Sal. Primer Margomulyo 50-51 & 1,70 & 28,55 & 1,52 & 0,18 \\
\hline Sal. Primer Margomulyo 51-52 & 1,70 & 28,55 & 1,52 & 0,18 \\
\hline Sal. Primer Kali Balong 45-52 & 2,50 & 65,66 & 2,96 & $-0,46$ \\
\hline Sal. Primer Kali Balong 52-53 & 2,60 & 65,66 & 2,91 & $-0,31$ \\
\hline
\end{tabular}

Sumber: Hasil analisis

\section{Perhitungan Pengaruh Backwater}

Perhitungan backwater dimaksudkan untuk mengetahui jarak pengaruh pasang surut air laut terhadap saluran. Hal ini perlu diperhatikan karena outlet saluran Primer Kali Balong berada di tepi laut. Perhitungan backwater ini menggunakan metode tahapan langsung (direct step method) [7] [8], yaitu dengan memperhitungkan jarak pengaruh yang ditimbulkan akibat pasang surut air laut yang tertinggi terhadap Saluran Primer Kali Balong. Adapun perhitungan pengaruh backwater dapat dilihat pada Tabel 10 dengan menggunakan Metode Tahapan Langsung [7].

Pada Tabel 10 panjang pengaruh backwater sebesar $1.494,85 \mathrm{~m}$.

Tabel 8. Perhitungan desain ulang saluran

\begin{tabular}{|c|c|c|c|c|c|}
\hline \multirow{2}{*}{ Nama Saluran } & $\begin{array}{c}\mathrm{h} \\
\text { exs }\end{array}$ & b exs & $\begin{array}{c}\mathrm{h} \\
\text { renc }\end{array}$ & $\begin{array}{c}\mathrm{b} \\
\text { renc }\end{array}$ & $\begin{array}{l}\mathrm{Q} \text { fc. } \\
\text { renc }\end{array}$ \\
\hline & $(\mathrm{m})$ & (m) & (m) & (m) & $\begin{array}{c}( \\
\mathrm{m}^{3} / \mathrm{det} \\
)\end{array}$ \\
\hline Sal. Sekunder Lontar 7-10 & 1,60 & 2,10 & 2,06 & 2,10 & 25,51 \\
\hline Sal. Sekunder Balong Sari 8-9 & 1,70 & 3,90 & 2,00 & 4,90 & 29,64 \\
\hline Sal. Sekunder Balong Sari 9-10 & 1,70 & 3,80 & 2,00 & 4,90 & 29,72 \\
\hline Sal. Sekunder Balong Sari 10-11 & 1,80 & 3,80 & 2,00 & 4,90 & 29,96 \\
\hline Sal. Sekunder Balong Sari 11-12 & 1,90 & 3,80 & 2,00 & 4,20 & 27,01 \\
\hline Sal. Sekunder Balong Sari 12-13 & 1,90 & 3,90 & 2,00 & 4,20 & 26,90 \\
\hline Sal. Sekunder Balong Sari 13-14 & 1,90 & 3,90 & 2,00 & 4,20 & 26,90 \\
\hline Sal. Sekunder Balong Sari 14-18 & 1,90 & 4,00 & 2,00 & 4,20 & 25,72 \\
\hline Sal. Sekunder Darmo Indah 24-25 & 1,10 & 4,00 & 1,30 & 4,80 & 12,22 \\
\hline Sal. Sekunder Darmo Indah 25-26 & 1,10 & 4,00 & 1,30 & 4,80 & 12,68 \\
\hline Sal. Sekunder Darmo Indah 26-28 & 1,20 & 3,50 & 1,30 & 4,10 & 11,71 \\
\hline Sal. Darmo Satelit 29-30 & 1,10 & 4,20 & 1,30 & 5,40 & 10,12 \\
\hline Sal. Darmo Satelit 30-31 & 1,20 & 4,20 & 1,30 & 5,40 & 9,78 \\
\hline Sal. Primer Gunungsari 43-42 & 1,50 & 5,20 & 1,70 & 7,00 & 8,83 \\
\hline Sal. Primer Kali Balong 40-44 & 2,45 & 12,00 & 2,70 & 14,20 & 66,98 \\
\hline Sal. Primer Kali Balong 44-45 & 2,45 & 12,00 & 2,70 & 14,20 & 68,02 \\
\hline Sal. Primer Kali Balong 45-52 & 2,50 & 13,00 & 2,70 & 14,50 & 69,33 \\
\hline Sal. Primer Kali Balong 52-53 & 2,60 & 13,00 & 2,70 & 14,50 & 69,33 \\
\hline
\end{tabular}

Sumber: Hasil analisis

Tabel 9. Perhitungan tinggi muka air setelah desain ulang saluran

\begin{tabular}{lcccc}
\hline & $\begin{array}{c}\mathrm{h} \\
\text { renc }\end{array}$ & Q renc & $\begin{array}{c}\mathrm{h} \text { muka } \\
\text { air } \\
\text { redesain }\end{array}$ & $\begin{array}{c}\Delta \mathrm{h}=\mathrm{h} \\
\text { renc }-\mathrm{h} \\
\text { muka } \\
\text { air }\end{array}$ \\
\cline { 2 - 5 } & $(\mathrm{m})$ & $\mathrm{m}^{3} / \mathrm{det}$ & $(\mathrm{m})$ & $(\mathrm{m})$ \\
\hline Sal. Sekunder Lontar 7-10 & 1,80 & 18,19 & 1,62 & 1,08 \\
Sal. Sekunder Balong Sari 8-9 & 1,80 & 26,37 & 1,80 & 0,20 \\
Sal. Sekunder Balong Sari 9-10 & 1,80 & 26,37 & 1,80 & 0,20 \\
Sal. Sekunder Balong Sari 10-11 & 1,80 & 26,37 & 1,79 & 0,21 \\
Sal. Sekunder Balong Sari 11-12 & 1,80 & 26,37 & 1,96 & 0,04 \\
Sal. Sekunder Balong Sari 12-13 & 1,80 & 26,37 & 1,97 & 0,03 \\
Sal. Sekunder Balong Sari 13-14 & 1,80 & 26,37 & 1,97 & 0,03 \\
Sal. Sekunder Balong Sari 14-18 & 1,80 & 26,37 & 1,99 & 0,01 \\
Sal. Sekunder Darmo Indah 24-25 & 1,10 & 11,64 & 1,22 & 0,08 \\
Sal. Sekunder Darmo Indah 25-26 & 1,10 & 11,64 & 1,20 & 0,10 \\
Sal. Sekunder Darmo Indah 26-28 & 1,10 & 11,64 & 1,29 & 0,01 \\
Sal. Darmo Satelit 29-30 & 1,10 & 9,22 & 1,22 & 0,08 \\
Sal. Darmo Satelit 30-31 & 1,10 & 9,22 & 1,28 & 0,02 \\
Sal. Primer Gunungsari 43-42 & 1,30 & 8,54 & 1,66 & 0,04 \\
Sal. Primer Kali Balong 40-44 & 2,30 & 66,65 & 2,69 & 0,01 \\
Sal. Primer Kali Balong 44-45 & 2,30 & 66,65 & 2,66 & 0,04 \\
Sal. Primer Kali Balong 45-52 & 2,30 & 66,65 & 2,70 & 0,00 \\
Sal. Primer Kali Balong 52-53 & 2,30 & 66,65 & 2,70 & 0,00 \\
\hline
\end{tabular}

Sumber: Hasil analisis 
Tabel 10. Perhitungan pengaruh backwater

\begin{tabular}{|c|c|c|c|c|c|c|c|c|c|c|c|c|}
\hline $\mathrm{H}$ & A & $\mathrm{P}$ & $\mathrm{R}$ & V & $\propto \frac{v^{2}}{2 g}$ & E & $\mathrm{DE}$ & \multirow{2}{*}{$\mathrm{Sf}$} & \multirow{2}{*}{ Sfrata $^{2}$} & \multirow{2}{*}{ So-Sfrata ${ }^{2}$} & \multirow{2}{*}{$\frac{X}{m}$} & \multirow{2}{*}{$\frac{\mathrm{DX}}{\mathrm{M}}$} \\
\hline M & $\mathrm{m}^{2}$ & M & M & $\mathrm{m} / \operatorname{det}$ & M & M & M & & & & & \\
\hline \multirow[t]{2}{*}{3,98} & 65,65 & 23,40 & 2,80 & 1,00 & 0,05 & 4,03 & & 0,000048 & & & & \\
\hline & & & & & & & 0,18 & & 0,00008 & 0,00090 & 195,71 & 195,71 \\
\hline \multirow[t]{2}{*}{3,80} & 62,32 & 23,00 & 2,71 & 1,05 & 0,06 & 3,86 & & 0,000061 & & & & \\
\hline & & & & & & & 0,10 & & 0,00010 & 0,00088 & 109,89 & 305,60 \\
\hline \multirow[t]{2}{*}{3,70} & 60,50 & 22,77 & 2,66 & 1,09 & 0,06 & 3,76 & & 0,000071 & & & & \\
\hline & & & & & & & 0,10 & & 0,00011 & 0,00086 & 111,39 & 417,00 \\
\hline \multirow[t]{2}{*}{3,60} & 58,68 & 22,55 & 2,60 & 1,12 & 0,06 & 3,66 & & 0,000081 & & & & \\
\hline & & & & & & & 0,10 & & 0,00009 & 0,00089 & 108,07 & 525,07 \\
\hline \multirow[t]{2}{*}{3,50} & 56,88 & 22,33 & 2,55 & 1,15 & 0,07 & 3,57 & & 0,000094 & & & & \\
\hline & & & & & & & 0,10 & & 0,00010 & 0,00087 & 109,39 & 634,46 \\
\hline \multirow[t]{2}{*}{3,40} & 55,08 & 22,10 & 2,49 & 1,19 & 0,07 & 3,47 & & 0,000110 & & & & \\
\hline & & & & & & & 0,10 & & 0,00012 & 0,00086 & 111,07 & 747,54 \\
\hline \multirow[t]{2}{*}{3,30} & 53,30 & 21,88 & 2,44 & 1,23 & 0,08 & 3,38 & & 0,000129 & & & & \\
\hline & & & & & & & 0,10 & & 0,00014 & 0,00084 & 113,23 & 858,77 \\
\hline \multirow[t]{2}{*}{3,20} & 51,52 & 21,66 & 2,38 & 1,27 & 0,08 & 3,28 & & 0,000151 & & & & \\
\hline & & & & & & & 0,09 & & 0,00016 & 0,00081 & 116,06 & 974,83 \\
\hline \multirow[t]{2}{*}{3,10} & 49,76 & 21,43 & 2,32 & 1,32 & 0,09 & 3,19 & & 0,000179 & & & & \\
\hline & & & & & & & 0,09 & & 0,00020 & 0,00078 & 119,82 & $1.094,65$ \\
\hline \multirow[t]{2}{*}{3,00} & 48,00 & 21,21 & 2,26 & 1,37 & 0,10 & 3,10 & & 0,000213 & & & & \\
\hline & & & & & & & 0,09 & & 0,00023 & 0,00074 & 124,97 & $1.219,62$ \\
\hline \multirow[t]{2}{*}{2,90} & 46,26 & 20,99 & 2,20 & 1,42 & 0,10 & 3,00 & & 0,000255 & & & & \\
\hline & & & & & & & 0,09 & & 0,00028 & 0,00069 & 132,24 & $1.351,86$ \\
\hline \multirow[t]{2}{*}{2,80} & 44,52 & 20,76 & 2,14 & 1,48 & 0,11 & 2,91 & & 0,000307 & & & & \\
\hline & & & & & & & 0,09 & & 0,00034 & 0,00064 & 142,99 & $1.494,85$ \\
\hline 2,70 & 42,80 & 20,54 & 2,08 & 1,53 & 0,12 & 2,82 & & 0,000372 & & & & \\
\hline
\end{tabular}

Sumber: Hasil analisis

6. Perhitungan Boezem

Perhitungan boezem direncanakan dengan tujuan menampung sementara debit limpasan sesuai kapasitas yang direncanakan [1],[8],[9]. Dalam perhitungan boezem menggunakan hidrograf rasional dengan rencana lama hujan 4 jam. Adapun perhitungan hidrograf rasional boezem dapat dilihat pada Tabel 11. Adapun grafik hidrograf boezem dapat dilihat pada Gambar 1.

Perhitungan selanjutnya yaitu menentukan volume dan kedalaman boezem. Untuk perhitungan kedalaman diperoleh dari volume dibagi luas. Pada Tabel 12 dihasilkan kedalaman yang terlalu tingggi $(5,27 \mathrm{~m})$, kedalaman ini tidak memungkinkan di lapangan, sehingga direncanakan kedalaman boezem setinggi 3,00 m saja. Dengan lahan yang tersedia direncanakan boezem seluas $26.000 \mathrm{~m}^{2}$ ditambah panjang long storage Saluran Kali Balong dan Margomulyo sebesar 16.8724,85 $\mathrm{m}^{2}$. Lokasi perencanaan boezem dilihat pada Gambar 2.

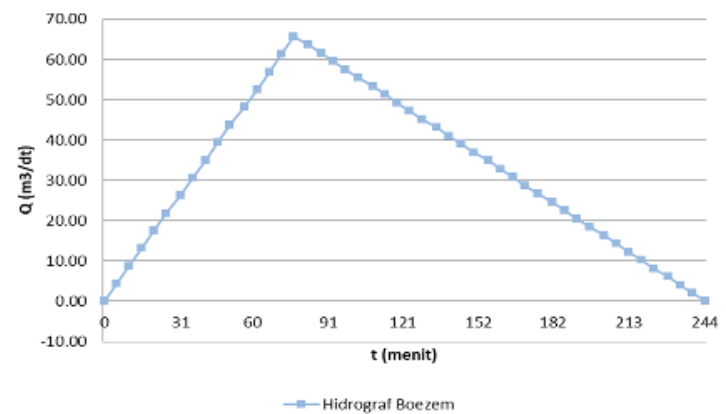

Gambar 1. Grafik Hidrograf Boezem Sumber: Hasil Analisis 
Tabel 11. Perhitungan Hidrograf Rasional Boezem

\begin{tabular}{|c|c|c|c|c|}
\hline $\begin{array}{c}\text { Durasi } \\
\text { hujan (t) } \\
\text { (Menit) }\end{array}$ & $\begin{array}{c}\text { Intensitas (I) } \\
(\mathrm{mm} / \mathrm{jam})\end{array}$ & (C) & $\begin{array}{c}\text { Luas (A) } \\
\mathrm{km}^{2}\end{array}$ & $\begin{array}{c}\text { Debit (Q) } \\
\left(\mathrm{m}^{3} / \mathrm{dt}\right)\end{array}$ \\
\hline 0,00 & 0,00 & 0,00 & 0,00 & 0,00 \\
\hline 5,19 & 37,53 & 0,48 & 13,11 & 4,38 \\
\hline 10,37 & 37,53 & 0,48 & 13,11 & 8,75 \\
\hline 15,56 & 37,53 & 0,48 & 13,11 & 13,14 \\
\hline 20,74 & 37,53 & 0,48 & 13,11 & 17,51 \\
\hline 25,93 & 37,53 & 0,48 & 13,11 & 21,89 \\
\hline 31,11 & 37,53 & 0,48 & 13,11 & 26,26 \\
\hline 36,30 & 37,53 & 0,48 & 13,11 & 30,64 \\
\hline 41,48 & 37,53 & 0,48 & 13,11 & 35,02 \\
\hline 46,67 & 37,53 & 0,48 & 13,11 & 39,40 \\
\hline 51,85 & 37,53 & 0,48 & 13,11 & 43,77 \\
\hline 57,04 & 37,53 & 0,48 & 13,11 & 48,15 \\
\hline 62,22 & 37,53 & 0,48 & 13,11 & 52,52 \\
\hline 67,41 & 37,53 & 0,48 & 13,11 & 56,91 \\
\hline 72,59 & 37,53 & 0,48 & 13,11 & 61,28 \\
\hline 77,78 & 37,53 & 0,48 & 13,11 & 65,66 \\
\hline 83,00 & 37,53 & 0,48 & 13,11 & 63,61 \\
\hline 88,21 & 37,53 & 0,48 & 13,11 & 61,56 \\
\hline 93,43 & 37,53 & 0,48 & 13,11 & 59,50 \\
\hline 98,65 & 37,53 & 0,48 & 13,11 & 57,45 \\
\hline 103,87 & 37,53 & 0,48 & 13,11 & 55,40 \\
\hline 109,08 & 37,53 & 0,48 & 13,11 & 53,35 \\
\hline 114,30 & 37,53 & 0,48 & 13,11 & 51,30 \\
\hline 119,52 & 37,53 & 0,48 & 13,11 & 49,24 \\
\hline 124,74 & 37,53 & 0,48 & 13,11 & 47,19 \\
\hline 129,95 & 37,53 & 0,48 & 13,11 & 45,14 \\
\hline 135,17 & 37,53 & 0,48 & 13,11 & 43,09 \\
\hline 140,39 & 37,53 & 0,48 & 13,11 & 41,04 \\
\hline 145,61 & 37,53 & 0,48 & 13,11 & 38,99 \\
\hline 150,82 & 37,53 & 0,48 & 13,11 & 36,93 \\
\hline 156,04 & 37,53 & 0,48 & 13,11 & 34,88 \\
\hline 161,26 & 37,53 & 0,48 & 13,11 & 32,83 \\
\hline 166,48 & 37,53 & 0,48 & 13,11 & 30,78 \\
\hline 171,69 & 37,53 & 0,48 & 13,11 & 28,73 \\
\hline 176,91 & 37,53 & 0,48 & 13,11 & 26,67 \\
\hline 182,13 & 37,53 & 0,48 & 13,11 & 24,62 \\
\hline 187,35 & 37,53 & 0,48 & 13,11 & 22,57 \\
\hline 192,56 & 37,53 & 0,48 & 13,11 & 20,52 \\
\hline 197,78 & 37,53 & 0,48 & 13,11 & 18,47 \\
\hline 203,00 & 37,53 & 0,48 & 13,11 & 16,41 \\
\hline 208,21 & 37,53 & 0,48 & 13,11 & 14,36 \\
\hline 213,43 & 37,53 & 0,48 & 13,11 & 12,31 \\
\hline 218,65 & 37,53 & 0,48 & 13,11 & 10,26 \\
\hline 223,87 & 37,53 & 0,48 & 13,11 & 8,21 \\
\hline 229,08 & 37,53 & 0,48 & 13,11 & 6,16 \\
\hline 234,30 & 37,53 & 0,48 & 13,11 & 4,10 \\
\hline 239,52 & 37,53 & 0,48 & 13,11 & 2,05 \\
\hline 244,74 & 37,53 & 0,48 & 13,11 & 0,00 \\
\hline
\end{tabular}

Sumber: Hasil analisis

\section{Perhitungan Pompa}

Direncanakan pompa sebanyak 8 unit dengan kapasitas $2,50 \mathrm{~m}^{3} / \mathrm{dt}$ yang bekerja dengan waktu tertentu. Adapun perhitungan inflow pada boezem dapat dilihat pada Tabel 13. Dan perhitungan Outflow pompa dapat dilihat pada Tabel 14.
Dari Hasil perhitungan dengan adanya kinerja pompa maka volume tampungan akhir boezem yang dibutuhkan sebesar 237.608,47 $\mathrm{m}^{3}$. Sedangkan tampungan boezem yang memungkinkan dilapangan sebesar $78.000 \mathrm{~m}^{3}$. ditambah panjang long storage Saluran Kali Balong dan Margomulyo sebesar $168.724,85 \mathrm{~m}^{3}$. Jadi keberadaan boezem dan tampungan alami sungai sudah mencukupi kebutuhan akan tampungan selama hujan. Adapun grafik hubungan hidrograf boezem dengan debit outflow pompa dapat dilihat pada Gambar 3.

Tabel 12. Perhitungan volume dan kedalaman boezem

\begin{tabular}{|c|c|c|c|c|}
\hline \multirow{2}{*}{$\mathrm{t}$} & \multicolumn{3}{|c|}{ Kolam } & \multirow{2}{*}{ Tinggi air } \\
\hline & $\mathrm{Q}_{\text {in }}$ & $\mathrm{Vol}_{\text {in }}$ & Vol $_{\text {in }}$ kumulatif & \\
\hline menit & $\mathrm{m}^{3} / \mathrm{dt}$ & $\mathrm{m}^{3}$ & $\mathrm{~m}^{3}$ & $\mathrm{~m}$ \\
\hline 0,00 & 0,00 & 0,00 & 0,00 & 0,00 \\
\hline 5,19 & 4,38 & 682,16 & 682,16 & 0,01 \\
\hline 10,37 & 8,75 & 2041,24 & 2723,40 & 0,03 \\
\hline 15,56 & 13,14 & 3408,19 & 6131,59 & 0,07 \\
\hline 20,74 & 17,51 & 4762,01 & 10893,61 & 0,12 \\
\hline 25,93 & 21,89 & 6134,22 & 17027,83 & 0,19 \\
\hline 31,11 & 26,26 & 7482,79 & 24510,62 & 0,27 \\
\hline 36,30 & 30,64 & 8860,25 & 33370,86 & 0,36 \\
\hline 41,48 & 35,02 & 10203,56 & 43574,43 & 0,48 \\
\hline 46,67 & 39,40 & 11586,28 & 55160,70 & 0,60 \\
\hline 51,85 & 43,77 & 12924,34 & 68085,04 & 0,74 \\
\hline 57,04 & 48,15 & 14312,30 & 82397,35 & 0,90 \\
\hline 62,22 & 52,52 & 15645,11 & 98042,46 & 1,07 \\
\hline 67,41 & 56,91 & 17038,33 & 115080,79 & 1,26 \\
\hline 72,59 & 61,28 & 18365,89 & 133446,68 & 1,46 \\
\hline 77,78 & 65,66 & 19764,36 & 153211,04 & 1,67 \\
\hline 83,00 & 63,61 & 20243,39 & 173454,43 & 1,90 \\
\hline 88,21 & 61,56 & 19563,19 & 193017,62 & 2,11 \\
\hline 93,43 & 59,50 & 18958,09 & 211975,72 & 2,32 \\
\hline 98,65 & 57,45 & 18315,45 & 230291,16 & 2,52 \\
\hline 103,87 & 55,40 & 17672,80 & 247963,96 & 2,71 \\
\hline 109,08 & 53,35 & 16997,53 & 264961,49 & 2,90 \\
\hline 114,30 & 51,30 & 16387,50 & 281349,00 & 3,07 \\
\hline 119,52 & 49,24 & 15744,86 & 297093,85 & 3,25 \\
\hline 124,74 & 47,19 & 15102,21 & 312196,06 & 3,41 \\
\hline 129,95 & 45,14 & 14431,86 & 326627,93 & 3,57 \\
\hline 135,17 & 43,09 & 13816,92 & 340444,84 & 3,72 \\
\hline 140,39 & 41,04 & 13174,27 & 353619,11 & 3,86 \\
\hline 145,61 & 38,99 & 12531,62 & 366150,73 & 4,00 \\
\hline 150,82 & 36,93 & 11866,20 & 378016,93 & 4,13 \\
\hline 156,04 & 34,88 & 11246,33 & 389263,26 & 4,25 \\
\hline 161,26 & 32,83 & 10603,68 & 399866,94 & 4,37 \\
\hline 166,48 & 30,78 & 9961,03 & 409827,97 & 4,48 \\
\hline 171,69 & 28,73 & 9300,53 & 419128,50 & 4,58 \\
\hline 176,91 & 26,67 & 8675,74 & 427804,24 & 4,67 \\
\hline 182,13 & 24,62 & 8033,09 & 435837,33 & 4,76 \\
\hline 187,35 & 22,57 & 7390,44 & 443227,78 & 4,84 \\
\hline 192,56 & 20,52 & 6734,87 & 449962,65 & 4,92 \\
\hline 197,78 & 18,47 & 6105,15 & 456067,79 & 4,98 \\
\hline 203,00 & 16,41 & 5462,50 & 461530,30 & 5,04 \\
\hline 208,21 & 14,36 & 4810,62 & 466340,92 & 5,10 \\
\hline 213,43 & 12,31 & 4177,21 & 470518,12 & 5,14 \\
\hline 218,65 & 10,26 & 3534,56 & 474052,68 & 5,18 \\
\hline 223,87 & 8,21 & 2891,91 & 476944,60 & 5,21 \\
\hline 229,08 & 6,16 & 2244,96 & 479189,55 & 5,24 \\
\hline 234,30 & 4,10 & 1606,62 & 480796,17 & 5,25 \\
\hline 239,52 & 2,05 & 963,97 & 481760,14 & 5,26 \\
\hline 244,74 & 0,00 & 321,32 & 482081,47 & 5,27 \\
\hline
\end{tabular}

Sumber: Hasil analisis 


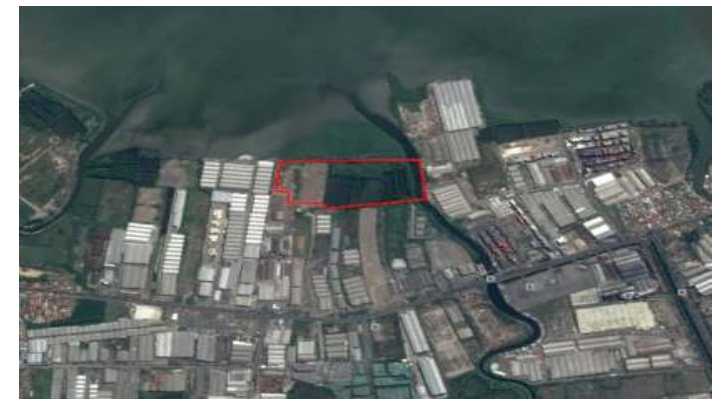

Gambar 2. Lokasi Boezem

Tabel 13. Perhitungan inflow pada boezem

\begin{tabular}{|c|c|c|c|}
\hline \multirow{2}{*}{$\mathrm{T}$} & \multicolumn{3}{|c|}{ Kolam } \\
\hline & $\mathrm{Q}$ in & Vol in & Vol in komulatif \\
\hline$(\min )$ & $\left(\mathrm{m}^{3} / \mathrm{dt}\right)$ & $\left(\mathrm{m}^{3}\right)$ & $\left(\mathrm{m}^{3}\right)$ \\
\hline 0,00 & 0,00 & 0,00 & 0,00 \\
\hline 5,19 & 4,38 & 682,16 & 682,16 \\
\hline 10,37 & 8,75 & $2.041,24$ & $2.723,40$ \\
\hline 15,56 & 13,14 & $3.408,19$ & $6.131,59$ \\
\hline 20,74 & 17,51 & $4.762,01$ & $10.893,61$ \\
\hline 25,93 & 21,89 & $6.134,22$ & 17.027 .83 \\
\hline 31,11 & 26,26 & $7.482,79$ & $24.510,62$ \\
\hline 36,30 & 30,64 & $8.860,25$ & $33.370,86$ \\
\hline 41,48 & 35,02 & $10.203,56$ & $43.574,43$ \\
\hline 46,67 & 39,40 & $11.586,28$ & $55.160,70$ \\
\hline 51,85 & 43,77 & $12.924,34$ & $68.085,04$ \\
\hline 57,04 & 48,15 & $14.312,30$ & $82.397,35$ \\
\hline 62,22 & 52,52 & $15.645,11$ & $98.042,46$ \\
\hline 67,41 & 56,91 & $17.038,33$ & $115.080,79$ \\
\hline 72,59 & 61,28 & $18.365,89$ & $133.446,68$ \\
\hline 77,78 & 65,66 & $19.764,36$ & $153.211,04$ \\
\hline 83,00 & 63,61 & $20.243,39$ & $173.454,43$ \\
\hline 88,21 & 61,56 & $19.563,19$ & $193.017,62$ \\
\hline 93,43 & 59,50 & $18.958,09$ & $211.975,72$ \\
\hline 98,65 & 57,45 & $18.315,45$ & $230.291,16$ \\
\hline 103,87 & 55,40 & $17.672,80$ & $247.963,96$ \\
\hline 109,08 & 53,35 & $16.997,53$ & $264.961,49$ \\
\hline 114,30 & 51,30 & $16.387,50$ & $281.349,00$ \\
\hline 119,52 & 49,24 & $15.744,86$ & $297.093,85$ \\
\hline 124,74 & 47,19 & $15.102,21$ & $312.196,06$ \\
\hline 129,95 & 45,14 & $14.431,86$ & $326.627,93$ \\
\hline 135,17 & 43,09 & $13.816,92$ & $340.444,84$ \\
\hline 140,39 & 41,04 & $13.174,27$ & $353.619,11$ \\
\hline 145,61 & 38,99 & $12.531,62$ & $366.150,73$ \\
\hline 150,82 & 36,93 & $11.866,20$ & $378.016,93$ \\
\hline 156,04 & 34,88 & $11.246,33$ & $389.263,26$ \\
\hline 161,26 & 32,83 & $10.603,68$ & $399.866,94$ \\
\hline 166,48 & 30,78 & $9.961,03$ & $409.827,97$ \\
\hline 171,69 & 28,73 & $9.300,53$ & $419.128,50$ \\
\hline 176,91 & 26,67 & $8.675,74$ & $427.804,24$ \\
\hline 182,13 & 24,62 & $8.033,09$ & $435.837,33$ \\
\hline 187,35 & 22,57 & $7.390,44$ & $443.227,78$ \\
\hline 192,56 & 20,52 & $6.734,87$ & $449.962,65$ \\
\hline 197,78 & 18,47 & $6.105,15$ & $456.067,79$ \\
\hline 203,00 & 16,41 & $5.462,50$ & $461.530,30$ \\
\hline 208,21 & 14,36 & $4.810,62$ & $466.340,92$ \\
\hline 213,43 & 12,31 & $4.177,21$ & $470.518,12$ \\
\hline 218,65 & 10,26 & $3.534,56$ & $474.052,68$ \\
\hline 223,87 & 8,21 & $2.891,91$ & $476.944,60$ \\
\hline 229,08 & 6,16 & $2.244,96$ & $479.189,55$ \\
\hline 234,30 & 4,10 & $1.606,62$ & $480.796,17$ \\
\hline 239,52 & 2,05 & 963,97 & $481.760,14$ \\
\hline 244,74 & 0,00 & 321,32 & $482.081,47$ \\
\hline
\end{tabular}

Sumber: Hasil analisis

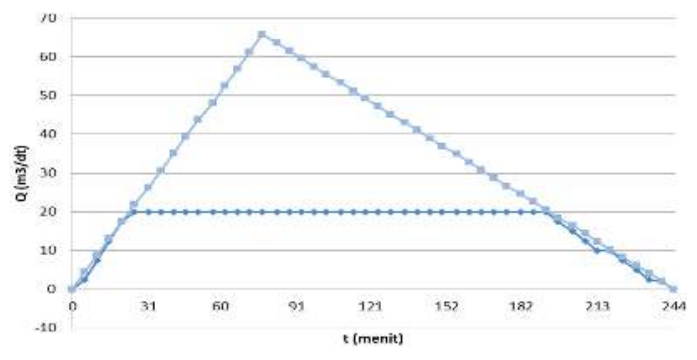

Gambar 3. Debit Outflow Pompa

8. Perhitungan Pintu Air

Pada perencanaan boezem ini direncanakan pintu air hidrolik yang terbuat dari profil baja. Pintu air direncanakan dengan lebar 1,50 $\mathrm{m}$ dan tinggi 4,00 m sebanyak 6 unit. Pengoperasian pintu air ini ditutup ketika terjadi pasang surut air laut dan dibuka ketika tidak terjadi pasang surut air laut.

- Tebal Pelat yang Diperlukan

Perhitungan untuk tebal pelat digunakan rumus sebagai berikut:

$\alpha=\frac{1}{2} * K *\left[\frac{a^{2}}{a^{2}+b^{2}}\right] *\left[\frac{b}{t}\right] * \mathrm{q}$

Keterangan:

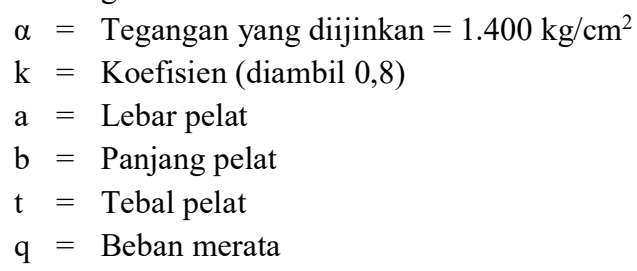

Maka:

$1400 \frac{\mathrm{kg}}{\mathrm{cm}^{2}}=\frac{1}{2} * 0,8 *\left[\frac{1,5^{2} \mathrm{~m}}{1,50^{2} \mathrm{~m}+4,00^{2} \mathrm{~m}}\right] *\left[\frac{1,50 \mathrm{~m}}{\mathrm{t}}\right] * 4050 \mathrm{~kg} / \mathrm{m}$

$1400 \frac{\mathrm{kg}}{\mathrm{cm}^{2}}=399,45 *\left[\frac{1,50 \mathrm{~m}}{\mathrm{t}}\right]$

$\mathrm{t}=2.036 \mathrm{~mm} \approx 20 \mathrm{~mm}$

9. Pengoperasian pompa dan Pintu

Pengoperasian pompa dan pintu bedasarkan batas peilschaal yang berada di hilir Kali Balong. Adapun gambar peilschaal dapat dilihat pada Gambar 4.

Pengoperasian pompa dan pintu air dapat dilihat di bawah ini:

- Keadaan 1 (Kondisi Hulu)

- Apabila muka air hulu berada dibatas siaga (warna kuning) sedangkan muka air hilir berada dibatas aman (warna hijau) maka pintu air dibuka dan pompa dimatikan.

- Apabila muka air hulu berada dibatas siaga (warna kuning) sedangkan muka air hilir berada lebih tinggi 
dari hulu dibatas siaga (warna kuning) maka pompa dioperasikan dan pintu ditutup.

- Apabila muka air hulu berada di batas aman (warna hijau) dan muka air hilir berada dibatas waspada (warna merah) maka pompa dimatikan dan pintu ditutup.

Tabel 14. Perhitungan outflow pompa

\begin{tabular}{|c|c|c|c|}
\hline \multicolumn{3}{|c|}{ Pompa } & \multirow{2}{*}{$\begin{array}{c}\text { Tampungan } \\
\text { Akhir }\end{array}$} \\
\hline Qout & Vol Out & $\begin{array}{l}\text { Vol Out } \\
\text { komulatif }\end{array}$ & \\
\hline$\left(\mathrm{m}^{3} / \mathrm{dt}\right)$ & $\left(\mathrm{m}^{3}\right)$ & $\left(\mathrm{m}^{3}\right)$ & $\left(\mathrm{m}^{3}\right)$ \\
\hline 0,00 & 0 & 0,00 & 0 \\
\hline 2,50 & 389 & 389,30 & 292,91 \\
\hline 7,50 & 1.554 & $1.943,30$ & 780,15 \\
\hline 12,50 & 3.114 & $5.057,30$ & $1.074,34$ \\
\hline 17,50 & 4.662 & $9.719,30$ & $1.174,36$ \\
\hline 20,00 & 5.839 & $15.558,00$ & $1.469,83$ \\
\hline 20,00 & 6.216 & $21.774,00$ & $2.736,62$ \\
\hline 20,00 & 6.228 & $28.002,00$ & $5.368,86$ \\
\hline 20,00 & 6.216 & $34.218,00$ & $9.356,43$ \\
\hline 20,00 & 6.228 & $40.446,00$ & $14.714,70$ \\
\hline 20,00 & 6.216 & $46.662,00$ & $21.423,04$ \\
\hline 20,00 & 6.228 & $52.890,00$ & $29.507,35$ \\
\hline 20,00 & 6.216 & $59.106,00$ & $38.936,46$ \\
\hline 20,00 & 6.228 & $65.334,00$ & $49.746,79$ \\
\hline 20,00 & 6.216 & $71.550,00$ & $61.896,68$ \\
\hline 20,00 & 6.228 & $77.778,00$ & $75.433,04$ \\
\hline 20,00 & 6.264 & $84.042,00$ & $89.412,43$ \\
\hline 20,00 & 6.252 & $90.294,00$ & $102.723,62$ \\
\hline 20,00 & 6.264 & $96.558,00$ & $115.417,72$ \\
\hline 20,00 & 6.264 & $102.822,00$ & $127.469,16$ \\
\hline 20,00 & 6.264 & $109.086,00$ & $138.877,96$ \\
\hline 20,00 & 6.252 & $115.338,00$ & $149.623,49$ \\
\hline 20,00 & 6.264 & $121.602,00$ & $159.747,00$ \\
\hline 20,00 & 6.264 & $127.866,00$ & $169.227,85$ \\
\hline 20,00 & 6.264 & $134.130,00$ & $178.066,06$ \\
\hline 20,00 & 6.252 & $140.382,00$ & $186.245,93$ \\
\hline 20,00 & 6.264 & $146.646,00$ & $193.798,84$ \\
\hline 20,00 & 6.264 & $152.910,00$ & $200.709,11$ \\
\hline 20,00 & 6.264 & $159.174,00$ & $206.976,73$ \\
\hline 20,00 & 6.252 & $165.426,00$ & $212.590,93$ \\
\hline 20,00 & 6.264 & $171.690,00$ & $217.573,26$ \\
\hline 20,00 & 6.264 & $177.954,00$ & $221.912,94$ \\
\hline 20,00 & 6.264 & $184.218,00$ & $225.609,97$ \\
\hline 20,00 & 6.252 & $190.470,00$ & $228.658,50$ \\
\hline 20,00 & 6.264 & $196.734,00$ & $231.070,24$ \\
\hline 20,00 & 6.264 & $202.998,00$ & $232.839,33$ \\
\hline 20,00 & 6.264 & $209.262,00$ & $233.965,78$ \\
\hline 20,00 & 6.252 & $215.514,00$ & $234.448,65$ \\
\hline 17,50 & 5.873 & $221.386,50$ & $234.681,29$ \\
\hline 15,00 & 5.090 & $226.476,00$ & $235.054,30$ \\
\hline 12,50 & 4.298 & $230.774,30$ & $235.566,67$ \\
\hline 10,00 & 3.524 & $234.297,80$ & $236.220,37$ \\
\hline 10,00 & 3.132 & $237.429,80$ & $236.622,93$ \\
\hline 7,50 & 2.741 & $240.170,30$ & $236.774,35$ \\
\hline 5,00 & 1.954 & $242.124,00$ & $237.065,55$ \\
\hline 2,50 & 1.175 & $243.298,50$ & $237.497,67$ \\
\hline 2,50 & 783 & $244.081,50$ & $237.678,64$ \\
\hline 0,00 & 392 & $244.473,00$ & $237.608,47$ \\
\hline
\end{tabular}

- Keadaan 2 (Kondisi Hilir)

- Apabila muka air hilir berada di batas aman (warna hijau) sedangkan muka air hulu berada dibatas waspada (warna merah) maka pintu air di buka dan pompa dimatikan.
- Apabila muka air hilir berada di batas siaga (warna kuning) sedangkan muka air hulu berada dibatas aman (warna hijau) maka pompa dioperasikan dan pintu ditutup.

- Apabila muka air hilir berada di batas waspada (warna merah) sedangkan muka air hulu berada dibatas waspada (warna merah) maka pintu ditutup dan pompa dioperasikan.

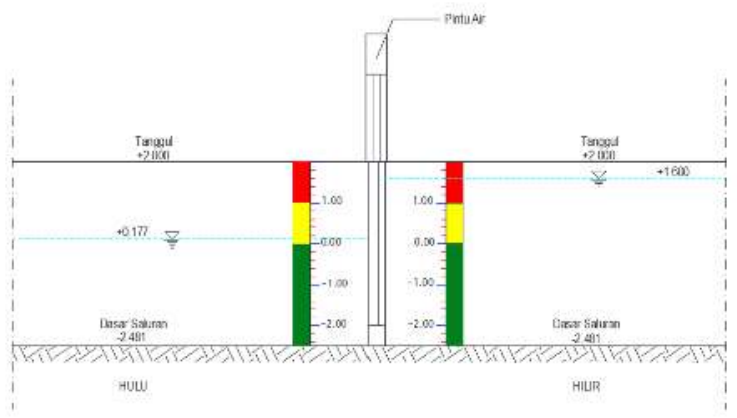

Gambar 4. Peilschaal

10. Waktu dan jumlah pengoperasian pompa

Direncanakan 8 unit pompa air dengan kapasitas 2,50 $\mathrm{m}^{3} /$ detik. Adapun waktu dan jumlah pengoperasian pompa dapat dilihat di bawah ini:

- Pada menit ke 5,19 pompa air dioperasikan 1 unit dengan kapasitas 2,50 $\mathrm{m}^{3} /$ detik.

- Pada menit ke 10,37 pompa air dioperasikan 3 unit dengan kapasitas 2,50 $\mathrm{m}^{3} /$ detik.

- Pada menit ke 15,56 pompa air dioperasikan 5 unit dengan kapasitas 2,50 $\mathrm{m}^{3} /$ detik.

- Pada menit ke 20,74 pompa air dioperasikan 7 unit dengan kapasitas 2,50 $\mathrm{m}^{3} /$ detik.

- Pada menit ke 25,93 sampai 192,56 pompa air dioperasikan 8 unit dengan kapasitas 2,50 $\mathrm{m}^{3} /$ detik.

- Pada menit ke 197,78 pompa air dioperasikan 7 unit dengan kapasitas 2,50 $\mathrm{m}^{3} /$ detik.

- Pada menit ke 203,00 pompa air dioperasikan 6 unit dengan kapasitas $2,50 \mathrm{~m}^{3} /$ detik.

- Pada menit ke 208,21 pompa air dioperasikan 5 unit dengan kapasitas $2,50 \mathrm{~m}^{3} /$ detik.

- Pada menit ke 213,43 sampai 218,65 pompa air dioperasikan 4 unit dengan kapasitas 2,50 $\mathrm{m}^{3} /$ detik

- Pada menit ke 223,87 pompa air dioperasikan 3 unit dengan kapasitas $2,50 \mathrm{~m}^{3} /$ detik.

- Pada menit ke 229,08 pompa air dioperasikan 2 unit dengan kapasitas $2,50 \mathrm{~m}^{3} /$ detik.

- Pada menit ke 234,30 sampai 239,52 pompa air dioperasikan 1 unit dengan kapasitas 2,50 $\mathrm{m}^{3} /$ detik 
- Pada menit ke 244,74 pompa air dimatikan.

\section{Simpulan}

Simpulan yang dapat diambil dari hasil studi ini antara lain adalah:

1. Curah hujan harian rencana untuk periode ulang 5 dan 10 tahun pada daerah studi adalah sebesar $117,09 \mathrm{~mm}$ dan $127,78 \mathrm{~mm}$

2. Terdapat beberapa saluran yang meluber diantaranya Saluran Sekunder Lontar, Balongsari, Darmo Indah, Darmo Satelit, Saluran Primer Gunungsari, dan Kali Balong.

3. Pemecahan masalah untuk menanggulangi saluran yang meluber adalah dengan mendesain ulang saluran eksisting dengan merubah lebar dan tinggi saluran, karena pada lokasi studi memungkinkan untuk dilakukan desain ulang saluran.

4. Terdapat pengaruh backwater akibat pasang surut air laut. hasil perhitungan diketahui bahwa panjang pengaruhnya adalah sebesar 1494,85 m.

5. Selain mendesain ulang saluran alternatif pemecahan masalah yang lain yaitu merencanakan boezem yang dilengkapi pompa dan pintu air.

6. Pada Perhitungan boezem direncanakan seluas $26.000 \mathrm{~m}^{2}$ dengan tinggi $3 \mathrm{~m}$ sehingga volume tampungannya sebesar $78.000 \mathrm{~m}^{3}$ ditambah panjang long storage Saluran Kali Balong dan Margomulyo sebesar 168.724,85 $\mathrm{m}^{3}$.

7. Pada perhitungan pompa direncanakan pompa submersible sebanyak 8 unit dengan kapasitas $2,50 \mathrm{~m}^{3} /$ detik. Debit akhir outflow pada saat pompa dioperasikan sebesar $244.473 \mathrm{~m}^{3}$.

8. Pada perhitungan pintu air direncanakan selebar $1,50 \mathrm{~m}$ dan tinggi 4,00 m sebanyak 6 unit.

9. Dari gambar peilschaal diketahui apabila muka air hulu berada dibatas siaga (warna kuning) sedangkan muka air hilir berada dibatas aman (warna hijau) maka pintu air dibuka dan pompa dimatikan. Dan juga sebaliknya, apabila muka air hilir berada dibatas waspada (warna merah) sedangkan muka air hulu berada dibatas waspada (warna merah) maka pintu ditutup dan pompa dioperasikan.

10. Pengoperasian pompa berdasarkan pada waktu. Pada menit ke 5,19 pompa air dioperasikan 1 unit, menit ke 10,37 dioperasikan 3 unit, menit ke 15,56 dioperasikan 5 unit, menit ke 20,74 dioperasikan 7 unit, menit ke 25,93 sampai 192,56 dioperasikan 8 unit, menit ke 197,78 dioperasikan 7 unit, menit ke 203 dioperasikan 6 unit, menit ke 208,21 dioperasikan 5 unit, menit ke 213,43 sampai 218,65 dioperasikan 4 unit, menit ke 223,87 dioperasikan 3 unit, menit ke 229,08 dioperasikan 2 unit, menit ke
234,30 sampai 239,52 dioperasikan 1 unit dan menit ke 244,74 pompa air dimatikan.

\section{Daftar Pustaka}

[1] S. K. Aziz, "Pola Pengendalian Banjir pada Bagian Hilir Saluran Primer Wonorejo Surabaya," J. Apl. Tek. Sipil, vol. 9, no. 2, p. 33, Aug. 2011.

[2] BMKG, "Laporan Pasang Surut Air Laut Kali Balong Tahun 2017," Surabaya, 2017.

[3] B. Triatmodjo, Hidrologi Terapan, Edisi 2. Yogyakarta: Beta Offset, 2008.

[4] I. S. Sosrodarsono, Hidrologi untuk Pengairan, Edisi 9. Jakarta: PT Pradnya Paramita, 1976.

[5] P. Buntung Peketingan, "Laporan Data Hujan Stasiun hujan Kandangan,” Surabaya, 2014.

[6] Soewarno, Hidrologi Aplikasi Metode Statistik untuk Analisa Data. Bandung, 1995.

[7] Suripin, Sistem Drainase Perkotaan yang Berkelanjutan. Semarang: Andi Yogyakarta, 2003.

[8] J. Loebis, Banjir Rencana Untuk Bangunan Air. Jakarta: Badan Penerbit Pekerjaan Umum, 1987.

[9] Anggrahini, Hidrolika Saluran Terbuka. Surabaya: CV Citra Media, 1996. 